\title{
Discussões Político-Partidárias no Facebook: 0 limite entre a liberdade de expressão e a intolerância
}

\author{
Alanda Maria Ferro Pereira', Nívea Kelly Santos da Silva ${ }^{1}$, Kathleen \\ Caroline de Lima Carlos ${ }^{1}$, Sheyla Fernandes ${ }^{1}$ e Renata Vera ${ }^{2}$ \\ 1Universidade Federal de Alagoas, Brasil | alanda-maria@outlook.com;
falecomkellysilva@hotmail.com; kathleenlimapsi@gmail.com; sheyla.fernandes@ip.ufal.br | \\ https://orcid.org/0000-0003-3638-319X; https://orcid.org/0000-0001-8823-4933; \\ https://orcid.org/0000-0003-1696-2602; https://orcid.org/0000-0003-4759-1314 \\ 2Universidade Federal da Bahia, Brasil | renatameiraveras@gmail.com | \\ https://orcid.org/0000-0002-1681-1401
}

\begin{abstract}
Resumo: Introdução. O Facebook despertou o interesse de muitos pesquisadores ao se tornar a maior rede social do mundo, tendo em vista que o anonimato possibilita que muitos usuários postem comentários intolerantes sem se preocuparem com as consequências ou punições por suas ações. Objetivo. Realizar uma análise das discussões político-partidária no Facebook. Método. Trata-se de um estudo qualitativo de caráter exploratório e descritivo em que foram selecionadas publicações relevantes de grupos e páginas referentes às discussões político-partidária no Facebook. Os comentários destas publicações foram reunidos em dois corpus e os conteúdos textuais processados no software IRAMUTEQ. Resultados. O primeiro corpus indicou a formação de 4 classes, (1) Eleição (27\%); (2) Discurso Político (29,7\%); (3) Oposições (24.3\%) e (4) Crimes Políticos (18.9\%). O segundo corpus indicou a formação de 2 classes, (1) "Legado do antigo governo" $(52,2 \%)$ e (2) "Consequências do atual governo" (47,8\%). Conclusões. as discussões político-partidárias se ancoram em visões de mundo estereotipadas e alguns elementos referentes ao formato de interação virtual estão na base da expressão aberta e violenta de intolerância política.
\end{abstract}

Palavras-chave: Rede Social; Intolerância; Política.

Political and Party Discussions on Facebook: The Limit between Freedom of Expression and Intolerance.

\begin{abstract}
Introduction: Facebook sparked the interest of many researchers by becoming the largest social network in the world, given that anonymity allows many users to post intolerant comments without worrying about the consequences or punishments for their actions. Objective: Conduct an analysis of the comments of political party intolerance on Facebook. Method: It is an exploratory and descriptive qualitative study in which relevant publications from groups and pages referring to political party discussions on Facebook were selected. The comments of these publications were gathered in two corpus and the textual contents were processed using the IRAMUTEQ software. Results: The first corpus indicated the formation of 4 classes, (1) Election (27\%); (2) Political Discourse (29.7\%); (3) Oppositions (24.3\%) and (4) Political Crimes (18.9\%). The second corpus indicated the formation of 2 classes, (1) "Legacy of the old government" $(52,2 \%)$ and (2) "Consequences of the current government" $(47,8 \%)$. Conclusions. party-political discussions are anchored in stereotyped worldviews and some elements referring to the format of virtual interaction are at the base of the open and violent expression of political intolerance.
\end{abstract}

Keywords: Social Network; Intolerance; Policy.

\section{Introdução}

A internet é tida como uma das principais tecnologias de comunicação e informação da contemporaneidade (Pereira Neto, et al., 2015). Segundo Hart (2004) "nenhuma outra tecnologia se difundiu tão rapidamente entre a população do planeta" (p.22), isso tem fortes implicações na vida dos internautas, pois de acordo com Castells (2003), a internet está se tornando o principal meio de comunicação e organização em todas as atividades e certamente os movimentos sociais e políticos também farão uso dela visto que se trata de um instrumento privilegiado capaz de atuar, informar, recrutar, organizar, dominar e contradominar populações. 
Com efeito, a internet vem transformando a vida em sociedade na medida em que hábitos culturais são re-significados e formas diversas de relacionamentos através das redes sociais online que vem ganhando cada dia mais adeptos (Sobrinho, Antunes \& Wanderbrook, 2016).

Nesse contexto, destaca-se a rede social Facebook por ser $02^{\circ}$ site mais acessado do Brasil e do mundo (Sobrinho \& Antunes, 2014), chegando a atingir em meados de 2017 cerca de 2 bilhões de usuários (Rede Brasil Atual, 2017). Esta rede social criada em 2004, por Mark Zuckerberg, Eduardo Saverin, Dustin Moskovitz e Chris Hughes, surgiu com objetivo inicial de promover a interação entre a comunidade de Harvard. Ao obter ampla aceitação por parte dos universitários, o site rapidamente se expandiu para as demais universidades e foi aberto ao público em geral dois anos após sua criação (Kirkpatrick, 2011).

O Facebook possui uma multiplicidade de ferramentas e aplicativos, assim como apresenta um fácil manuseio, atraindo cada vez mais usuários. Ademais, esta rede social apresenta um diferencial em relação a outras redes de relacionamento online, pois permite ao usuário o controle de privacidade, mantendo o anonimato (Kirkpatrick, 2011; Bousso et al., 2014; Correia \& Moreira, 2014; Sobrinho, Antunes \& Wanderbrook, 2016).

Estudos apontam que este anonimato possibilita que muitos usuários postem comentários intolerantes sem se preocuparem com as consequências ou punições por suas ações (Rosa \& Santos, 2014; Rodrigues, 2015). Para Korne (2017), a intolerância é entendida como uma atitude que além de empregar rejeição a algo ou alguém, busca combatê-lo fazendo-se uso da imposição, psíquica ou religiosa, podendo ser um fenômeno individual ou até mesmo coletivo. Trata-se de estar em posse de uma verdade absoluta e que se faz impor por meio da anuência ou repressão (Passos, 2017).

Ramos (2017) evidencia que o Facebook apesar de seus pontos positivos, "vem se configurando como veículo que denota uma teia de relações sociais conflituosas no tocante às discussões polêmicas" (p.208), a exemplo do debate de questões políticas.

Em 2016, a Agência Nova S/B realizou uma pesquisa para analisar a intolerância das postagens das redes sociais como Facebook, Twitter e Instagram e constatou que 97,4\% das postagens relacionadas à política possuíam conteúdos intolerantes. Desse modo, temse claro que o Facebook, enquanto uma rede de relacionamentos online, apresenta-se como um campo rico para o estudo dos comportamentos intolerantes.

$\mathrm{Na}$ área da ciência psicológica, uma teoria bastante utilizada para predizer e explicar comportamentos consiste na Teoria da Ação Planejada (TAP). A TAP foi desenvolvida a partir da atualização da Teoria da Ação Racional (TAR) (Fishbein \& Ajzen, 1975; Ajzen \& Fishbein, 1980). Ambas as teorias consideram que antes das ações ocorre um sistemático processo de análise das informações disponíveis (Corner \& Sparks, 2020). Acessando tal processo, torna-se possível a previsão dos comportamentos.

Desta forma, segundo os pressupostos da TAR, o comportamento é resultado imediato das intenções. As intenções, por sua vez, resultam da relação entre as atitudes e as crenças normativas. As atitudes referem avaliações subjetivas sobre um determinado alvo. $E$ as crenças se originam das informações disponíveis sobre determinado objeto, podendo ser verídicas ou não (Fishbein \& Ajzen, 2011).

Derivadas das crenças normativas, a norma subjetiva representa a pressão social para a realização do comportamento (Fishbein \& Ajzen,1975; Ajzen \& Fishbein, 1980), trata-se da interferência das pessoas de seus grupos de pertença sobre uma determinada ação (ex.: vizinhos, familiares, amigos).

Ajzen (1991) atualizou o modelo da TAR, introduzindo a percepção de controle para realização do comportamento. A noção das dificuldades e facilidades em executar uma ação indica o nível de controle que a pessoa julga possuir para a realizar. A inclusão do controle percebido no modelo da TAR originou a TAP. 
Levando em consideração o modelo da TAP, especificamente no que se refere à articulação entre crenças e ações, o presente estudo tomou como base a seguinte questão de pesquisa: Como se se configuram as discussões político-partidárias no Facebook?

\section{Metodologia}

Para responder ao objetivo de analisar as discussões político-partidárias no Facebook, especialmente, responder como se configuram as crenças dentro deste contexto, foi desenvolvido um estudo qualitativo de caráter exploratório e descritivo. Inicialmente, foram selecionados os mais relevantes grupos e páginas do Facebook cujo foco são as discussões Político-Partidárias.

A utilização das redes socais online como contexto de coleta de dados é um procedimento cada vez mais frequente, tendo em vista sua ampla utilização para comunicação em uma diversidade de fins (Fernandes et al., 2020a). Após a seleção dos sítios, foram coletados os comentários das publicações de maior destaque em dois momentos distintos: (1) os comentários das 20 publicações mais relevantes no período do mês de janeiro de 2018; (2) os comentários das 20 publicações mais relevantes no período do mês de setembro de 2019, (2018 e 2019), totalizando 40 publicações.

Os critérios estabelecidos para a seleção destes grupos e páginas foram: (1) abordar os assuntos pertinentes à política; (2) serem abertos; (3) terem um número mínimo de dez mil membros/seguidores e (4) serem brasileiros. Para a busca tanto dos grupos, quanto das páginas, foram utilizados 02 descritores (Política e Político), os resultados obtidos encontram-se na Tabela 1.

Tabela 1. Grupos e páginas referentes às Discussões Político-Partidárias no Facebook.

\begin{tabular}{|c|c|c|}
\hline Descritor & Grupo & Membros \\
\hline Política & $\begin{array}{l}\text { Políticas, crimes e } \\
\text { fatos de Itaboraí }\end{array}$ & $33.486 \mathrm{mil}$ \\
\hline Político & $\begin{array}{l}\text { Bibo Nunes - Debate } \\
\text { Político }\end{array}$ & $29.149 \mathrm{mil}$ \\
\hline Descritor & Página & Membros \\
\hline \multirow[t]{2}{*}{ Política } & $\begin{array}{l}\text { Vamos falar de } \\
\text { política? }\end{array}$ & $73.954 \mathrm{mil}$ \\
\hline & Política no face II & $249.543 \mathrm{mil}$ \\
\hline
\end{tabular}

A Tabela 1, mostra que com o descritor "Política" foram selecionados um grupo e duas páginas com 33.486 mil, 73.954 e 249.954 mil membros, respectivamente, já com o descritor "Político" foi selecionado apenas um grupo com 29.149 mil membros. Percebese que as páginas abertas representam maior adesão por parte dos usuários do Facebook em comparação aos grupos abertos.

Os comentários foram importados para o editor de texto OpenOffice Writer, constituindo assim dois corpus de análise, formados pelos comentários dos usuários do Facebook em relação às publicações de conteúdo político postados nos grupos e páginas desta rede social nos dois períodos de busca apresentados anteriormente.

Após a elaboração do corpus, os conteúdos textuais foram processados no software de análises de dados textuais IRAMUTEQ. Trata-se de um software de origem francesa, gratuito e disponível online, elaborado por Pierre Ratinaud que permite fazer diferentes tipos de análise de dados envolvendo tabelas indivíduos/palavras, desde as análises simples como a lexicografia básica que trata a lematização e o cálculo de frequência de palavras, até análises multivariadas (Camargo \& Justo, 2013). 
Neste estudo, foi utilizado o Método de Classificação Hierárquica Descendente (CDH) ou Método de Reinert para analisar os dados.

A Classificação Hierárquica Descendente (CHD) analisa os Segmentos de Textos (ST) que foram classificados de acordo com seus respectivos vocabulários, levando em consideração a frequência $(f)$ e qui-quadrado $\left(x^{2}\right)$, o que possibilita a criação de classes de Unidades de Contexto Elementares (UCEs) formadas com as palavras com vocabulário similar entre si, mas ao mesmo tempo distintos das demais UCEs das outras classes (Camargo \& Justo, 2013a). De forma mais específica, por meio da CHD é possível obter como resultado uma figura ilustrativa das classes que posteriormente são descritas, interpretadas e definidas pelos pesquisadores. Conforme tutorial disponível para a utilização do software (Camargo \& Justo, 2013b):

"A partir dessas análises em matrizes o software organiza a análise dos dados em um dendograma da CHD, que ilustra as relações entre as classes. O programa executa cálculos e fornece resultados que nos permite a descrição de cada uma das classes, principalmente, pelo seu vocabulário característico (léxico) e pelas suas palavras com asterisco (variáveis). Além disto, o programa fornece uma outra forma de apresentação dos resultados, através de uma análise fatorial de correspondência feita a partir da CHD. Com base nas classes escolhidas, o programa calcula e fornece-nos os segmentos de texto mais característicos de cada classe (corpus em cor) permitindo a contextualização do vocabulário típico de cada classe. O que são estas classes de palavras e de segmentos de texto? Em nível do programa informático, cada classe é composta de vários segmentos de texto em função de uma classificação segundo a distribuição do vocabulário (formas) destes segmentos de texto." (Camargo \& Justo, 2013b, p. 5).

A Figura 1 apresenta a estruturação sequencial que parte de um nível mais amplo para um nível mais restrito do material utilizado para análise pelo programa. Com base nos segmentos de texto é possível indicar o sentido das palavras destacadas por meio da frequência e qui-quadrado, viabilizando a interpretação dos resultados.

\section{Corpus}

(conjunto de textos)

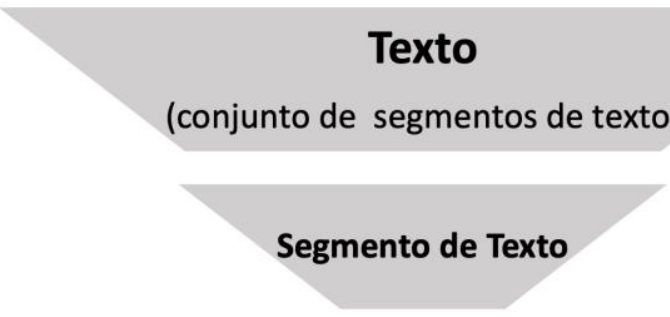

Fig. 1. Noções de corpus, texto e segmentos de texto (Camargo \& Justo, 2013b)

\section{Resultados e Discussão}

Na primeira análise, correspondente ao mês de janeiro de 2018, do corpus "Discussões Político-Partidárias no Facebook pré-eleições de 2018", proveniente da transcrição dos comentários dos grupos e páginas selecionados, foram observadas 1.973 ocorrências de palavras, sendo 816 formas distintas. Este corpus foi dividido em 58 segmentos de textos e destes, 34 , ou seja, $58,62 \%$ foram consideradas na Classificação Hierárquica Descendente $(\mathrm{CDH})$. 
A CDH dividiu-se em 4 classes (Figura 2), a classe 1 nomeada "Eleição", representou 27\% do corpus, a classe 2 intitulada "Discurso Político" representou 29,7\%, a classe 3 nomeada "Oposições" representou 24,3\% e a classe 4 intitulada "Crimes Políticos", representou $18,9 \%$ do corpus.

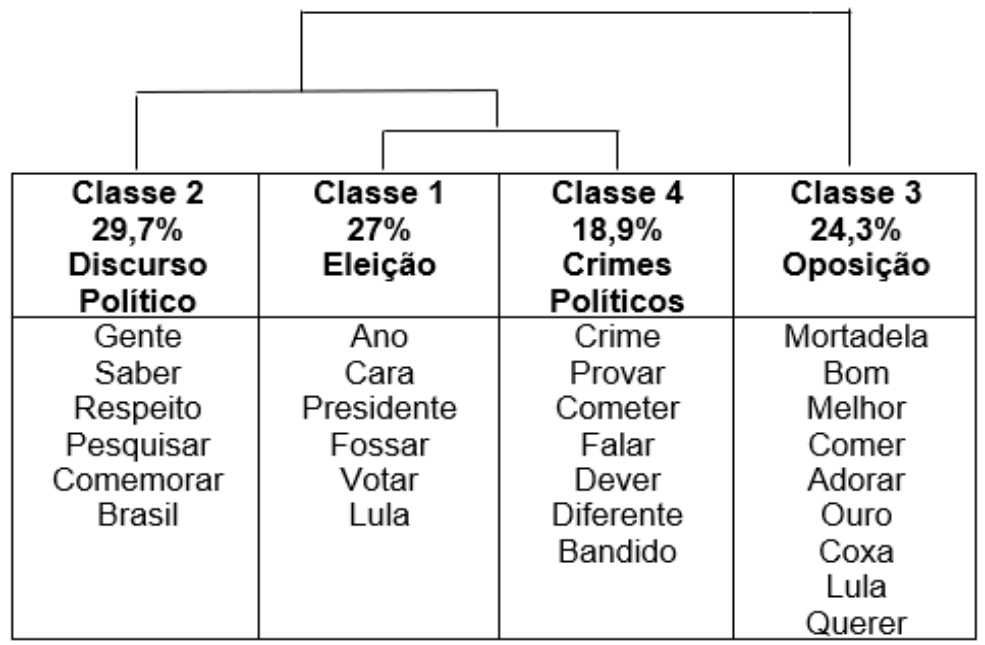

Fig. 2. Dendograma Discussões Político-Partidárias no Facebook 2018.

Globalmente, os resultados reportados no dendograma chamam a atenção para a estreita relação entre os vocábulos de destaque e o período da coleta de dados, tratava-se do ano das eleições para presidência da república no Brasil.

A classe 1 faz menção ao nome do ex presidente Lula, além de outras palavras que ao mesmo tempo canalizam o debate entre direita e esquerda no contexto político-partidário no Brasil, na figura de Lula e Bolsonaro, e polarizam as crenças externalizadas nos comentários:

Referindo-se a Lula - "Eu não entendo a burrice desse povo querer votar num marginal!"; "Presidente tem que governar para todos, não para castas";

Referindo-se a Bolsonaro - "Não seja ridículo ele será presidente não para subir morro algum e sim para governar dando rumos decentes ao nosso Brasil".

De fato, a polarização nas eleições já vinha sendo demonstrada a partir de discursos de ódio no Facebook desde 2014. Para Brugnago e Chaia (2015), alguns movimentos sociais de luta por direitos, por exemplo as manifestações do Passe Livre ocorridas em 2013 em São Paulo, uniram simpatizantes da direita e da esquerda contra o aumento das passagens de transportes públicos, porém logo os grupos voltaram a rivalizar dando início aos discursos de intolerância nas redes sociais.

A classe 2 demonstra, de acordo com as crenças expressas nos comentários, a importância de estar atento às informações para votar com consciência e ter a chance de comemorar um Brasil livre de corrupção e evidencia também a polarização das opiniões já observada na classe 1: "ao invés de fazer uma pesquisa imparcial para descobrir a veracidade dos fatos, você prefere viver na ignorância"; "brasileiro vota em quem a pesquisa mostra que está ganhando"; "Qualquer pesquisa que se faça, até àquelas nos grupos, na família, nas rodinhas de amigos, dá Bolsonaro disparado, então, só pode ser piada, brincadeira, a pesquisa dele".

Alguns estudiosos vêm demonstrando a influência das redes sociais na escolha política dos indivíduos. Em 2004, Deleuze (2004) apontava que o marketing já estava sendo instrumento de controle social. Da Empoli (2019) aponta que as fake news, as teorias da conspiração e os algoritmos nas redes sociais estão sendo utilizados para disseminar ódio e influenciar nas eleições, como o que aconteceu com Donald Trump nos Estados Unidos da América em 2016/2017 e de Jair Bolsonaro no Brasil em 2018/2019. 
Inclusive, o uso desses algoritmos gerados a partir de mídias sociais como Facebook, Instagram e Google Adwords está cada vez mais servindo às campanhas eleitorais, conforme destaca Da Empoli (2019).

A classe 3 demonstra as oposições dos partidos políticos citados pelos usuários do Facebook, representados por "Mortadela" versus "Coxa/Coxinha", ou seja, partido de esquerda (Lula) em contraposição ao partido de direita (Bolsonaro): "São Petralhas até quando chegar o último sanduba de mortadela!"; "Tem muita coxinha querendo abrir as pernas para mortadela".

Essa nova classe denominada de coxinha denotava o seu conservadorismo e tentava apresentar o Partido dos Trabalhadores como a expressão pura da esquerda, passando a atribuir-lhe características como comunista e corrupta por natureza, apelidando os de esquerda como petralhas em referência aos Irmãos Metralha da Disney (Brugnago \& Chaia, 2015). Observa-se a utilização de termos pejorativos para referir a oposição e denegrir seus ideais, no entanto, é imprescindível realçar que essas condutas se constituem como uma via de mão dupla, não sendo particulares a um ou outro lado dessa disputa ideológica.

Na classe 4, nota-se que os usuários do Facebook se referem às denúncias dos crimes políticos, evidenciando que não basta apenas falar ou comentar acerca dos crimes políticos, mas é preciso prová-los: "Lula é condenado, Bolsonaro é também, o crime é diferente, mas crime é crime"; "O crime do Lula foi dar um pouco de condições aos pobres. E esse crime é gravíssimo para elite".

É necessário destacar que a mídia contribuiu para a ideologia de ódio no âmbito político. Para Brum (2018), a mídia dominante participa ativamente da propagação das relações de falseação da verdade pelo mecanismo ideológico e elegendo objetos desejáveis e indesejáveis. Nesse caso, a ideologia de esquerda se configurou através da mídia como o problema causador da desestabilização que vem afetando os sistemas políticoeconômicos e simbólicos. Por esse motivo foi eleita como inimigo a ser eliminado. A mídia, inclusive se utilizou das inúmeras fragilidades jurídicas da Operação Lava Jato, criada para desvendar os crimes de corrupção, corroborando para divulgação de trechos cujo propósito era a obtenção da repulsa da opinião pública contra os principais suspeitos apontados pela operação (Silva, 2020).

Na segunda análise, correspondente ao mês de setembro de 2019, um ano e oito meses após a primeira coleta, foi possível observar no corpus "Discussões Político-Partidárias no Facebook pós-eleições de 2018", 10.715 ocorrências de palavras, sendo 2.049 formas distintas. Este corpus foi dividido em 296 segmentos de textos considerados na Classificação Hierárquica Descendente (CDH), com aproveitamento de 63,79\%.

A CDH dividiu-se em 2 classes, a classe 1, nomeada "Legado do antigo governo" representou $52,2 \%$ do corpus e a classe 2 , intitulada "Consequências do atual governo" representou $47,8 \%$, conforme apresenta o Dendograma que segue:

\begin{tabular}{|c|c|}
\hline \multicolumn{1}{c|}{} & \multicolumn{1}{|c|}{$\mid$} \\
\hline $\begin{array}{c}\text { Classe 1 } \\
\mathbf{5 2 , 2} \% \\
\text { Legado do } \\
\text { antigo governo }\end{array}$ & $\begin{array}{c}\text { Classe 2 } \\
\mathbf{4 7 , 8} \% \\
\text { Consequências } \\
\text { do atual } \\
\text { governo }\end{array}$ \\
\hline Pessoa & Intervenção \\
Merda & militar \\
Brasil & Política \\
Governo & Borracha \\
País & Bando \\
Deputado & Bala \\
Presidente & Vagabundo \\
Brasileiro & Gado \\
Maconha & Parabéns \\
Haddad & Ditadura \\
Apoio & Pimenta \\
& Idiota \\
\hline \multicolumn{2}{|c}{} \\
\hline
\end{tabular}

Fig. 3. Dendograma Discussões Político-Partidárias no Facebook 2019. 
Pode-se perceber na Figura 3, que a classe 1 apresentou aspectos críticos relacionados ao antigo governo, culpabilizando a gestão anterior pelo caótico cenário político, social, econômico e educacional brasileiro. Comentários pejorativos a respeito do nível educacional do antigo presidente e da capacidade intelectual dos seus apoiadores foram prevalentes. O cenário de crise econômico-financeira foi associado às tentativas de implantação do socialismo ao comparar a conjuntura político brasileira com o contexto da Venezuela, propondo que o novo governo foi o responsável pela salvação da economia e não aderência ao regime, e também, aos casos de corrupção do antigo governo divulgados na mídia nacional. As acusações de corrupção foram atreladas à figura do ex-presidente Lula e ao seu partido (Partido dos Trabalhadores) de forma negativa. As minorias sociais foram duramente criticadas por estarem na pauta do antigo governo e o posicionamento político mostrou-se como conservador de direita: "o Brasil não foi quase socialista graças a pessoas como o Bolsonaro"; "um partido que em vez de arrumar emprego para as pessoas terem dignidade e poderem comprar seus bens de consumo criou um povo dependente de bolsa família e auxílio isso e aquilo"; "o congresso teve que aprovar um bilhão pra pagar a fiança da Venezuela e outro país aí que o PT foi fiador, isso é uma merda"; e "Lula era chefe de quadrilha, analfabeto, ladrão e condenado, os apoiadores dele são iguais, todos lixo".

Silva (2020) atenta para o fato de que o governo de Bolsonaro mantém os mesmos discursos de ódio observados na campanha eleitoral: anticientificista, populista, com rastros fascistas e revestido de uma pseudodemocracia orientado pelo seu guru Olavo de Carvalho. Este por sua vez funciona nesse governo como uma espécie de metapolítica responsável pela compilação de teorias conspiratórias. Assim, no pacote de conspirações de Bolsonaro, orientado por Olavo de Carvalho, há as tramas de que o marxismo cultural difundido nas universidades é um plano de dominação global dos comunistas, difundindo o ódio da população contra as universidades e partidos de esquerda. Os discursos de ódio do governo Bolsonaro são apoiados também na repressão policial, sintetizando o lema 'bandido bom é bandido morto', contribuindo para as reações violentas contra o inimigo eleito pelo governo como responsável por qualquer dificuldade econômica no país.

A classe 2 apresentou aspectos relacionados às consequências negativas da atual gestão, o discurso irônico e pejorativo foi estabelecido ao expressar previsões catastróficas para a nova administração presidencial à medida que resultados econômicos, políticos e educacionais mostraram-se insatisfatórios. Grupos apoiadores do atual governo vêm sentindo as consequências da má gestão, demonstrando descontentamento e arrependimento pela escolha política realizada nas eleições, tecendo críticas ao grupo do qual faziam parte. A defesa da intervenção militar foi duramente criticada e combatida nos comentários, os apoiadores da volta do regime foram lembrados desse período sombrio da história brasileira, suas consequências, injustiças e vítimas. A oposição mostrou-se de esquerda, comentários pejorativos foram associados ao comportamento, posicionamento e discurso do atual presidente, e também dos seus apoiadores: "toma seus bobos, vocês são da turma do Bolsonaro, vai apanhando e treinando para intervenção militar já"; "apanharam e ganharam uma amostra grátis da intervenção militar"; "era pra ter metido a borracha no povo, não pediram intervenção militar, votem no bostonaro de novo na próxima eleição"; "tá aí a intervenção militar que vocês estão pedindo, gados" e "vermes bolsominions tudo com cara de otário, tem que ferrar gado pedindo intervenção militar".

De acordo com Zago (2020), tanto as publicações como os comentários de cunho opinativo, sejam políticos ou não, buscam sobrepujar a opinião divergente em uma tentativa de a calar, cessar seu local de fala, tratando o outro como um inimigo a ser aniquilado em nome da democracia. A liberdade de expressão que se configura como um direito de todos, acaba por ultrapassar a linha tênue que a separa da intolerância e os discursos de ódio se tornam prevalentes nos ambientes virtuais cujos temas de interesse por natureza são embasados em conflitos ideológicos. Além disso, a falta de controle do material veiculado nas redes sociais amplia a fragilidade no controle da violência que se traduz em um campo fértil para a exteriorização de atitudes intolerantes (Fernandes et al, 2020a; Fernandes et al, 2020b). 
Considerando o modelo teórico da TAP e os resultados aqui apresentados, pode-se inferir que, dadas as circunstâncias das crenças expressas no Facebook, incluindo-se aqui o fato de terem sido coletadas em um contexto de eleições políticas, a função dessa forma virtual de polarização pode aludir a diversas configurações de intolerância que se revelam transpostas à barreira digital, implicando na necessidade de reconhecimento dos elementos inerentes ao campo cibernético das relações interpessoais e intergrupais e de seu papel nas formas de comunicação entre as pessoas. Os resultados demonstram dimensões agregadas das normas subjetivas e do controle comportamental percebido que podem ser refletidos em termos da adesão, reprodução e expansão das crenças ideológicas que parecem ser expostas praticamente sem nenhuma dificuldade e com amplo caráter de rivalidade entre os grupos.

\section{Conclusões}

O presente estudo propôs uma análise das crenças de intolerância político-partidárias no Facebook no sentido de refletir sobre os limites entre a liberdade de expressão e a intolerância política. Os resultados demonstraram pelo menos três considerações mais relevantes: (1) a utilização das redes sociais online para disseminação de discursos de ódio é crescente; (2) páginas e grupos cujos temas de interesse giram em torno de debates ideológicos se configuram como cenários ideais para polarização de opiniões e expressão de violência; (3) a fonte dos discursos de ódio não é unilateral, mas deriva de um processo de retroalimentação entre as partes envolvidas, culminando em um sistema progressivo de expressão de intolerância.

Para além dessas considerações, é pertinente também ressaltar que o mundo virtual estabelece uma conexão próxima com o mundo das relações presenciais, podendo ambos serem reflexos das facetas distintas do mundo real. Deste modo, investigações que se debrucem em analisar as relações virtuais e seus contornos são notavelmente oportunas, ainda mais em um contexto em que é crescente o uso das redes sociais para comunicação e interação entre as pessoas. Destacamos também que a teoria utilizada como base para a investigação, a TAP, possibilitou descrever aspectos relevantes das configurações das discussões político-partidárias na medida em que lança luz à facilidade com que a intolerância é exposta no Facebook, assim como, a forma favorecida em que o quadro de conflito ideológico é claramente reproduzido e compartilhado. Essas considerações realçam a necessidade de se explorar os aspectos relacionados à expressão de intolerância cibernética que cada vez mais se torna incisiva e propagada nas redes sociais.

Outro aspecto significativo deste estudo é concernente ao Software utilizado como ferramenta para analisar os dados coletados. O IRAMUTEQ se mostrou importante para a realização das análises uma vez que possibilitou a organização e compilação das crenças, a partição destas em classes e o destaque dos vocábulos mais salientes, com isso, foi possível estabelecer as associações e distanciamentos dos discursos de modo a apreender globalmente a expressões de intolerância política no Facebook e como sua expressão ocorre.

Mesmo atingindo seus objetivos, esta investigação apresenta algumas lacunas. A primeira se refere ao período restrito da coleta de dados. As informações coletadas representam apenas uma parcela dos conteúdos publicados nas páginas selecionadas em dois meses específicos, sendo um no período antecedente às eleições brasileiras de 2018 e outro posterior às eleições (no ano seguinte). Possivelmente a inserção de outros períodos possibilitaria uma análise mais robusta da intolerância política, assim como o exame de outros aspectos relativos à sua natureza e manutenção. Deste modo, pesquisas futuras devem ser encorajadas a ampliar essas informações ao considerarem períodos mais abrangentes de coleta de dados, além de outras redes sociais online, como Twitter e Instagram, por exemplo, além de coletar informações junto a internautas, o que possibilitaria uma análise detalhada da associação entre os construtos da TAP e, portanto, uma explicação para a facilidade com que a intolerância virtual se multiplica nas redes sociais online. 


\section{Referências}

Ajzen, I. (1991). The theory of planned behavior. Organizational Behavior and Human Decision Process, v. 50, n. 2, p. 179-211, DOI:10.1016/07495978(91)90020-T

Ajzen, I.\& Fishbein, M. (1980). Understanding attitudes and predicting social behavior. New Jersey: Prentice-Hall.

Bousso, R. S.,Ramos,D., Frizzo, H. C. F., Santos, M. R., \& Bousso, F. (2014). Facebook: um novo lócus para a manifestação de uma perda significativa. Psicologia USP,25 (2), 172-179. doi: https://doi.org/10.1590/0103-656420130022

Brugnago, F., Chaia, V. (2014). A nova polarização política nas eleições de 2014: radicalização ideológica da direita no mundo contemporâneo do Facebook. Aurora - revista de arte, mídia e política, vol. 7, n.1., 99-129. doi: 10.23925/1982-6672

Brum, J. C. (2018). Violência e política no Brasil: um olhar sobre o discurso intolerante na mídia digital. Linguagem \& Ensino, vol. 21, n.2, p. 63-77.

Camargo, B. V.; \& Justo, A. M. (2013a). IRAMUTEQ: Um Software Gratuito para Análise de Dados Textuais. Temas em Psicologia, vol. 21, no 2, 513-518.

Camargo, B. V.; \& Justo, A. M. (2013b) Tutorial para uso do software de análise textual IRAMUTEQ. Florianopolis-SC: Universidade Federal de Santa Catarina.

Conner, M \& Spark, P. (2020). Theory of Planned Behaviour and Health Behaviour. In Conner Mark. Theory of planned behavior. Handbook of Sport Psychology, p. 3.

Correia, P. M. A. R., \& Moreira, M.F. R.(2014). Novas formas de comunicação: história do Facebook - Uma história necessariamente breve. ALCEU, Rio de Janeiro, v. 14, n.28, p.168187 ,jan./jun.

D'amorim, M. A. (2000). A teoria da ação racional nos comportamentos de saúde. Temas em Psicologia, v. 8, n. 1, p. 39-44.

Dossiê: Intolerância visíveis e invisíveis no mundo digital - Nova/sb, 2016.

Fernandes, Sheyla et al., (2020a) Relações raciais digitais: um estudo sobre as formas de expressão da intolerância racial no Facebook. Revista Ibérica de Sistemas e Tecnologias de Informação, n. 38, p. 79-91.

Fernandes, Sheyla et al., (2020b). Relações raciais no facebook: análise de comentários acerca de conteúdos raciais digitais. New Trends in Qualitative Research, v. 4, p. 317-329.

Fernandes, Sheyla Christine Santos et al., (2019). Teoria da Ação Planejada como suporte teórico e metodológico: uma aplicação da Teoria da Ação Planejada. Interação em Psicologia, v. 23, n. 1, apr., Curitiba.

Ajzen, I., \& Fishbein, M. (1975). A Bayesian analysis of attribution processes. Psychological bulletin, 82(2), 261.

Fishbein, M., \& Ajzen, I. (2011). Predicting and changing behavior: The reasoned action approach. Taylor \& Francis.

Kirkpatrick, D. (2011). O efeito Facebook: os bastidores da história da empresa que mais conecta o mundo. Rio de Janeiro: Intrínseca.

Körner, K. (2017). As muitas manifestações da intolerância. REVER, Ano 17, № 3, set/dez. p.5978.

Lahlou S. (2012). Text mining methods: an answer to Chartier and Meunier. Papers on Social Representations [Internet]. v.7, p. 1-39.

Marchand, P.; P. Ratinaud. (2012). L'analyse de similitude appliqueé aux corpus textueles: les primaires socialistes pour l'election présidentielle française. Em: Actes des 11eme Journées internationales d'Analyse statistique des Données Textuelles. JADT 2012. p.687-699. Presented at the 11eme Journées internationales d'Analyse Statistique des Données Textuelles. JADT 2012. Liège, Belgique.

Mara e Rosa, G. A.; \& Santos, B. R. (2014). Facebook: negociação de identidades e o medo da violência. Arquivos Brasileiros de Psicologia, v.66, n.1, 18-32, Rio de Janeiro. 
Moutinho, K.; Roazzi, A. (2010). As teorias da ação racional e da ação planejada: relações entre intenções e comportamentos. Avaliação psicológica, v. 9, n.2, p. 279-287.

Passos, J. D. (2017). A intolerância religiosa: mecanismos e antídotos. REVER, Ano 17, № 3, set/dez.

Pereira Neto, A., et al., (2015). O paciente informado e os saberes médicos: um estudo de etnografia virtual em comunidades de doentes no Facebook. História, Ciências, Saúde Manguinhos, v.22, supl., p.1653-1671, Rio de Janeiro.

Ramos, E. B. (2017). POLÍTICA, Preconceito, ideologia e antipetismo nas páginas de direita do facebook no ano eleitoral de 2014. Albuquerque: revista de historia. vol. 9, n. 17, jan.-jul., p. 206-236.

Ratinaud P. (2009). IRAMUTEQ: Interface de R pour les Analyses Multidimensionnelles de Textes et de Questionnaires [Computer software]. Disponível em: http://www.iramuteq.org.

Rede Brasil Atual (2017). Disponível em: <http://www.redebrasilatual.com.br/blogs/blog-narede/2017/07/facebook-2-bilhoes-de-usuarios-e-um-projeto-para-dominar-o-mundo >. Acesso em: Out.2017.

Rodrigues, H. (2015). Intolerância na Rede. Tribuna do Planalto. Disponível em: $<$ http://tribunadoplanalto.com.br/indee.php?option=com_content\&view=article\&id=19095:201 4-09-27-03-31-18\&catid=55: ciencia-e-tecnologia\&ltemid=43> .

Silva, C.G.C. (2020). O bolsonarismo da esfera pública. Uma análise foucaultiana sobre os conceitos de pós-verdade, fake News e discurso de ódio presentes nas falas de Bolsonaro. Dissertação apresentada no Programa de Pós Graduação em Letras da Universidade Federal do Amazonas.

Sobrinho, E. M.; Antunes, M. C.; \& Wanderbrook, A. C. N. S. (2016). Significados e Influências do Facebook na Rede Relacional de Adultos. Bol. Acad. Paulista de Psicologia, São Paulo, Brasil - V. 36, n. 90, p. 48-65.

Soral W, Bilewicz M, Winiewski M. Exposure to hate speech increases prejudice through desensitization. Aggress Behav. 2018 Mar;44(2):136-146. doi: 10.1002/ab.21737. Epub 2017 Nov 2. PMID: 29094365.

Zago, L. F.; DOS SANTOS, A. B. A. (2020). Pedagogias da Polarização no Facebook: redes sociais online e urgência opinativa. Reflexão e Ação, v. 28, n. 3, p. 133-150. 